\title{
Ciencias de las Religiones y teología: un diálogo necesario'
}

\author{
Religious Sciences and theology: \\ a necessary dialogue
}

\section{Resume $n$}

\begin{abstract}
Este artículo aborda el tema "Ciencias religiosas y teología: un diálogo necesario". Para ello son necesarias la modestia, la apertura y la colaboración: (a) modestia en reconocer con honestidad intelectual el carácter provisional y los límites de la obra misma, sin, por tanto, desvalorizarla o considerarla irrelevante; (b) apertura para aceptar con lealtad contribuciones de otras fuentes de estudio del fenómeno religioso; (c) colaboración para enriquecer y enriquecer el discurso interdisciplinario. Teniendo como trasfondo o punto de partida de la Teología como "conocimiento parcial sobre un objeto parcial", se presentan razones y argumentos en torno a seis disciplinas que buscan dialogar con el área de Ciencia de las Religiones, a saber: Filosofía de la Religión, Fenomenología de la Religión, Psicología de la Religión. Religión, Sociología de la Religión, Historia de las Religiones y Antropología de la Religión.
\end{abstract}

Palabras clave: Ciencias de las religiones. Diálogo. Interdisciplinariedad. Pluralidad. Teología.

\section{A bstract}

This article addresses the theme "Religious Sciences and Theology: A necessary dialogue". For this, modesty, openness and collaboration are necessary: (a) modesty in recognizing with intellectual honesty the provisional character and limits of the work itself, without, therefore, devaluing it or considering it irrelevant; (b) openness to loyally accept contributions from other sources of study of the religious phenomenon; (c) collaboration to enrich and enrich interdisciplinary discourse. Having as a background or starting point from Theology as "partial knowledge about a partial object", reasons and arguments are presented around six disciplines that seek to dialogue with the Science of Religions area, namely: Philosophy of Religion, Phenomenology of Religion, Psychology of Religion, Sociology of Religion, History of Religions and Anthropology of Religion.

Keywords: Religion studies. Dialogue. Interdisciplinarity. Plurality. Theology.

\section{Introducción} reflexiones del libro Nuevo paradigma teológico (Tamayo, 2009b) y, para esta publicación, fue revisada y adaptada tecnicamente por el profesor e investigador Renato Kirchner (PUC-Campinas) y por el estudiante de doctorado y mestre Felipe de Queiroz Souto (UFJF).

2 Universidad Carlos III, Cátedra de Teología y Ciencias de las Religiones Ignacio Ellacuría. Calle Madrid, 126, Edificio López Aranguren 15.0.03, 28903, Getafe, Madrid, España. E-mail: <juanjotamayo@gmail.com>. 
mortíferas se han dejado sentir con especial criminalidad en Brasil. Espero podamos vernos pronto presencialmente. Conservo un grato recuerdo de todas y todos ustedes, muchos de cuyos nombres y rostros tengo en la memoria. Deseo expresarles mi felicitación por la celebración de este Simposio sobre Ciencias de las Religiones y Teología, tema de necesario tratamiento en este momento de búsqueda teológico-interdisciplinar, que abre nuevos horizontes tanto al quehacer teológico como a las disciplinas que se ocupan del estudio de las religiones, espiritualidades y sabidurías. Y con mi felicitación, mi agradecimiento por esta nueva invitación, que es para mi un honor, un privilegio y un placer (Juan José Tamayo).

El tema propuesto es "Ciencias de las Religiones: un diálogo necesario". Y la primera pregunta a plantear puede parecer ociosa entre personas que nos dedicamos al quehacer teológico como tarea, profesión y vocación desde hace varias décadas y en mi caso durante más de medio siglo: ¿Qué es la teología? ¿Cómo definirla? Dependiendo de la respuesta podrá establecerse un diálogo o no con las ciencias de las religiones.

En los comienzos de mis estudios de teología a finales de los sesenta y principios de los setenta del siglo pasado en un seminario de Castilla - se llamaba Seminario Conciliar de San José, pero no por el concilio Vaticano II, sino por el Concilio de Trento -, recuerdo la definición que teólogo (en masculino) daba el arzobispo anglicano William Temple, un prestigioso ecumenista invitado como observador al concilio Vaticano II, me imagino que no exenta de humor británico: "Un teólogo es una persona muy sensata y sesuda que pasa toda una vida encerrado entre libros intentando dar respuestas exactísimas y precisas a preguntas que nadie se plantea" (Tamayo, 2004, online).

Humor británico aparte, esa era la imagen de las personas dedicadas a la teología: teólogos varones, clérigos, que enseñaban la "ciencia sagrada" de la teología en los seminarios, centros teológicos e incluso facultades de teología anteriores al Concilio Vaticano II.

Fue a principios de los setenta del siglo pasado cuando encontré una nueva definición de teología que sintonizaba con la tesis doctoral que por entonces estaba preparando en la Universidad Pontificia de Salamanca en el libro de Gustavo Gutiérrez, Teología de la liberación, que dio origen a una corriente de teología del mismo nombre y de cuya publicación de la primera edición estamos celebrando el 50 aniversario: La teología es la reflexión crítica sobre la praxis histórica a la luz de la Palabra (Gutiérrez, 1971). Una teología que, bajo la influencia de la tesis XI de Marx sobre Feuerbach, no se limita a pensar el mundo, a interpretarlo, sino que constituye un momento del proceso a través del cual el mundo es transformado.

La teología es en primer lugar reflexión crítica sobre sí misma, sobre sus fundamentos, de la sociedad y de las religiones. Es teoría crítica a la luz de la fe desde una hermenéutica emancipadora, animada por una intencionalidad ética e indisolublemente unida a la praxis histórica de la liberación. Gutiérrez subraya la doble función de la teología así entendida: la espiritual, que remite a la experiencia religiosa de encuentro con el Dios de los empobrecidos, el Dios del éxodo y de la esperanza de los pobres y el Dios de la liberación, y la racional como inteligencia de la fe en diálogo entre fe y razón.

\section{La teología, "saber parcial sobreun objeto parcial"}

Ahora bien, la teología así entendida no agota la reflexión sobre Dios, ni el estudio de las religiones en general o de cada religión en particular. No abarca todos los campos de análisis de la realidad religiosa. 
Es uno más entre los numerosos caminos y formas de aproximación a la experiencia de lo sagrado. Coincido con Pohier (1978, p. 226) en que la teología es un "[...] saber parcial sobre un objeto parcial" y en que "[...] el conocimiento de Dios es [...] algo fragmentario, aleatorio y limitado [...], no porque Dios no sea el infinito, sino porque yo soy finito".

En un texto de gran fuerza expresiva Pohier relativiza el carácter totalizador que se reconocía a la teología en épocas pasadas.

Hoy [afirma] no puedo concebir la teología como esas extraordinarias catedrales del saber sobre Dios, donde la inteligencia avanzaba en el conocimiento del misterio divino con toda intrepidez de una epistemología pseudoaristotélica o con el aplomo de un Cayetano, un Juan de Santo Tomás o un Maritain. No me siento a gusto, por otra parte, con las pretensiones - también exorbitadas a fin de cuentas - de las teologías de la historia de la salvación, convencidas de que puedan dominar y abarcar toda la realidad de la historia tan fácilmente como las teologías "metafísicas" de antaño creían captar el ser y todas sus modalidades (Pohier, 1978, p. 227).

Por eso, la teología tiene que dialogar, e incluso confrontarse, con otras ciencias o disciplinas que también se ocupan de Dios, de los dioses, las diosas y las religiones desde otros métodos y enfoques. La actitud de los teólogos y las teólogas ante otras disciplinas que se mueven en el mismo ámbito de estudio ha de ser de modestia, apertura y colaboración: (a) Modestia para reconocer con honestidad intelectual el carácter provisional y los límites de su propio trabajo, sin por ello minusvalorarlo o considerarlo irrelevante; (b) Apertura para acoger con lealtad las aportaciones de las otras fuentes de estudio del fenómeno religioso; (c) Colaboración para enriquecerse y enriquecer el discurso interdisciplinar.

La teología es un género literario que tiene sus propias reglas de juego o, si se prefiere, una disciplina con su propio estatuto de autonomía. Es, por expresarnos en términos de Wittgenstein, un "juego de lenguaje" que, como todo juego de lenguaje, tiene su Sitz im Leben (= contexto vital) y su propia gramática. Pero, a su vez, está dentro de una amplia red de comunicaciones con otras disciplinas. Vive en un régimen de "[...] dependencia en relación con las condiciones sociales de producción, es decir, con la economía de los bienes culturales, sobre los que los teólogos y las teólogas están llamados a ejercer una vigilancia ideopolítica permanente" (Boff, 1980, p. 301). De ahí la importancia de la sociología, la economía, la politología, la antropología cultural, la ecología, etc. como mediaciones necesarias del discurso teológico³.

La apertura de la teología se extiende también, y de manera prioritaria, a las diferentes disciplinas que se ocupan del estudio de la religión: filosofía de la religión, fenomenología de la religión, historia de las religiones, sociología de la religión, psicología de la religión, antropología de las religiones, ecología de las religiones, geografía de las religiones, etc. Siguiendo a M. Eliade, en estas disciplinas la palabra "religión" no implica de forma necesaria la creencia en Dios, dioses o espíritus, sino que se refiere a la experiencia de lo sagrado y se relaciona con los conceptos de ser, sentido y verdad (Eliade, 1998).

¿Cómo debe entenderse esa apertura? No al modo tradicional en que las diferentes disciplinas, y muy especialmente la filosofía, eran consideradas ciencias subordinadas y auxiliares que estaban al servicio de la teología y se sometían obedientemente a sus órdenes. Las disciplinas citadas son todas ellas "mayores de edad", autónomas y no necesitan pasar por el Jordán de la teología para conseguir su legitimidad intelectual y académica. Por ello, su relación ha de ser de diálogo, de colaboración y de crítica en sentido bidireccional.

Veamos algunas de las principales aportaciones de las diferentes ciencias de las religiones a la teología. Empecemos por la filosofía de la religión.

\footnotetext{
${ }^{3}$ Sobre la mediación socioanalítica en la teología de la liberación, verificar: Tamayo (2000b).
} 


\section{(a) Filos ofía de la religión}

La filosofía de la religión ${ }^{4}$ reflexiona sobre la racionalidad de las creencias religiosas y estudia las relaciones entre la fe y la razón. La crítica moderna de la religión, desde los maestros de la sospecha (Marx, Nietzsche y Freud) hasta nuestros días, juega un papel fundamental en esta disciplina. Dicha crítica impugna la credibilidad, legitimidad e incluso utilidad de la religión, sobre todo la cristiana 5 . Es verdad que en ella no faltan reduccionismos y dogmatismos, como ya viera Bloch cuando calificaba a la llustración de "roma" en materia religiosa. Sin embargo, plantea importantes problemas epistemológicos que la teología no puede eludir, hace luminosas aportaciones en torno al carácter ideológico del cristianismo que la teología haría bien en asumir o, al menos, analizar, y pone el dedo en la llaga sobre las perversiones de que con frecuencia es objeto la religión tanto en la teoría como en la práctica: irracionalismo, fideísmo, intolerancia, fanatismos, conciencia mágica, ideologización de la realidad, etc. Lejos de considerar la crítica de la religión como adversaria de la teología cristiana, yo creo que debe ser entendida como un impulso para la reflexión y un momento interno de la práctica teológica.

La religión se encuentra segura en manos de los filósofos, decía Nietzsche. Sin embargo, cuando sale del campo de la filosofía y pasa a manos de "supuestos profesionales", hay que echarse a temblar. La filosofía de la religión pregunta a la teología por la fundamentación de sus afirmaciones teológicas y por su relevancia en el plano epistemológico. La ayuda, a su vez, a tener precisión conceptual6.

El actual enfoque ha superado airosamente, a mi juicio, tres de los obstáculos teóricos que han dificultado el estudio objetivo de la religión a lo largo de la segunda mitad del siglo XX: (a) el prejuicio existencialista - sobre todo, heideggeriano -, que, al reconocer valor exclusivo al tiempo histórico, descuida la experiencia del tiempo cíclico; (b) el prejuicio cristiano-ortodoxo, que encierra a la religión en los límites de la interpretación dogmática de los primeros concilios y deja en la sombra las experiencias religiosas y culturales ecuménicas anteriores a Nicea; (c) el prejuicio posmoderno, que rechaza todo fundamento y todo gran relato. El estudio del fenómeno de lo sagrado tiene lugar hoy por vía polilógica. En esa perspectiva hay una recuperación del mito en cuanto palabra reveladora de una realidad viva, y no como fábula, impostura o enfermedad del lenguaje. Afirma García Bazán:

El mito y la historia - no se oponen, sino que son los dos modos irreductibles entre sí, pero complementarios, como los seres humanos han sido capaces de vivir finita y temporalmente la realidad de lo sagrado, habiendo producido a partir de sus concepciones, culturas y civilizaciones que han querido conservar estas vivencias (Bazán, 2000, p. 12).

Uno de los problemas centrales de la filosofía de la religión es Dios, que, según Hegel, constituye por igual el objeto de la filosofía y el de la religión?. Hay una correlación entre el problema de Dios y la filosofía, que ha ido evolucionando a lo largo de la modernidad europea, desde la armonía Dios-razón (con Descartes y Leibniz), pasando por la crisis del teísmo y la muerte de Dios, la consideración de absurdo semántico de la palabra "Dios" en la filosofía analítica, hasta el cuestionamiento radical de teodicea, por una parte, y los intentos de reconstrucción del teísmo, por otra. Estrada (1994) centra correctamente el debate actual sobre el teísmo en torno a estas preguntas:

\footnotetext{
4 Sobre la filosofía de la religión, consulte: Bataille (1975); Caffarena (1983); Caffarena y Mardones (1992); Caffarena y Velasco (1973); Fierro (1979); Fraijó Nieto (1994); Hegel (1981, 1984); Hume (1974); Instituto Fe y Secularidad (1973); Kant (1969, 1999); Mardones (1992); Sádaba (1978, 1989); Tamayo (1994) y Zubiri (1993).

${ }^{5}$ En este caso, consulte: Gimbernat (1993); Zirker (1985) y Weger (1985).

6 Para más información, consultar: Duméry (1957a) y Schäffler (1983).

7 Para obtener más información, consulte: Duméry (1957b); Estrada (1994, 1996, 1997, 2001); Gesché (1995, 1997); Miethe y Flew (1994); Queiruga (1997) y Tamayo (2000).
} 
¿Cuál es el estatuto del teísmo? ¿Cómo podemos fundamentar el pensamiento religioso y teológico? ¿Hasta qué punto está justificada la apelación al teísmo para dar respuesta a las preguntas humanas por el saber, hacer y esperar que planteaba Kant? ¿Qué significado pueden tener, si es que tienen alguno, las clásicas pruebas de la existencia de Dios a partir del hombre? (Estrada, 1994, p. 240).

\section{(b) Fe nomenología de Ia religión}

La fenomenología de la religión $n^{8}$ analiza los elementos comunes de la estructura religiosa, a partir de las manifestaciones, múltiples y variadas, complejas y ambiguas, del fenómeno religioso a lo largo de la historia: el ámbito de lo sagrado, el misterio como realidad determinante de lo sagrado, la actitud religiosa del sujeto, las mediaciones en que se presencializa el misterio, las expresiones de reconocimiento del misterio en la persona religiosa, los tiempos sagrados, las personas sagradas, las creencias y su formulación doctrinal, etc. La fenomenología ofrece, asimismo, una tipología de las religiones conforme a diferentes criterios: el cronológico, el de la forma de representar el misterio, el de la realidad que sirve de sujeto, el del carácter más personalizado o impersonal de la divinidad, etc. (Velasco, 1993).

Ahora bien, la fenomenología de la religión no se queda en el estudio de la estructura religiosa en el pasado. Se interesa, asimismo, por las posibilidades de realización - e incluso de supervivencia -, del hecho religioso en medio del actual pluralismo cultural - aspecto este que comparte con la sociología de la religión -, atendiendo a la crisis radical por la que están pasando las religiones y, sobre todo, las instituciones en que éstas se encarnan (Velasco, 1998).

Una de las líneas más prometedoras de la investigación fenomenológica actual sobre la religión es el estudio del fenómeno místico. Es opinión muy extendida - convicción, diría mejor -, entre los fenomenólogos de la religión que el estudio de la mística constituye uno de los caminos más directos para avanzar en el conocimiento de la verdad de la religión y para encontrarse con su núcleo más íntimo. Así lo entendía $\mathrm{H}$. Bergson, para quien la religión es la cristalización, operada por un enfriamiento intelectual, de lo que la mística vino a depositar, incandescente, en el alma de la humanidad (Fraijó Nieto, 2000). Por eso, la mística es considerada hoy como el elemento de mayor convergencia de las religiones. Ello explica el interés creciente que los estudios interdisciplinares de las religiones muestran por los místicos, sus experiencias espirituales y sus escritos 9 .

Dichos estudios desmienten que la mística sea un fenómeno a-histórico, oscurantista y generador de pasividad en la persona creyente. Lo que muestran, más bien, es que en la experiencia mística se compaginan armónicamente el pensar y el amar, la inteligencia y la afectividad, la espiritualidad y la teología. En el mundo místico el sujeto no queda eliminado o negado, sino que es afirmado y potenciado ${ }^{10}$.

La alternancia de opuestos es la forma como el místico expresa su experiencia más profunda: ausencia-presencia, silencio-palabra, desolación-consolación, dolor-gozo, invidencia-visión, muerte-vida, nesciencia-saber, desposesión-posesión, despojo-apropiación, prisión-libertad, soledad/acompañamiento, tinieblas-luz, etc. Es todo un cuestionamiento a la teología afirmativa y una invitación a reflexionar en clave dialéctica.

\footnotetext{
8 Sobre la filosofía de la religión, se recomienda: Duch (1978); Duméry (1958); Dupré (1999); Eliade (1967); Otto (1980); van der Leew (1964); Velasco $(1984,1992,1993)$ y Widengren (1976).

9 Para más información, estos autores pueden ser consultados: Eckhart (1998); Ibn'Arabi (1994); Izutsu (1997a, 1997b) y Panikkar (1996).

10 En este caso, consulte también: Haag (1998); James (1986); Scholem (1996); Schlütter y Faus (1998) y Velasco (1999).
} 
La mística cuenta hoy con una buena acogida más allá de la experiencia religiosa. Importantes científicos y pensadores no creyentes han sabido valorar adecuadamente su significación antropológica y su capacidad movilizadora en campos como la ciencia y el arte. Así lo expresa Einstein: "La más bella emoción que podemos tener es la mística. Ella es la fuerza de toda ciencia y arte verdaderos. Y para quien esta experiencia resulte extraña, es como si estuviera muerto" (Einstein apud Magdalena, 1998, p. 32).

\section{(c) Psicología de Ia religión}

La psicología de la religión se ocupa del estudio del impulso religioso: su origen y evolución, sus diferentes manifestaciones y motivaciones: miedo, consuelo, necesidad de amparo y protección, defensa frente a la naturaleza hostil'11. Uno de los análisis psicológicos de la religión más influyentes en la cultura moderna es el psicoanálisis freudiano, que estudia los procesos inconscientes que se producen en la persona. La oscura percepción de los factores psíquicos y de las relaciones de lo inconsciente, afirma Freud, se refleja en la construcción de una realidad sobrenatural, que la ciencia transforma en "psicología de lo inconsciente". El psicoanálisis freudiano considera la religión como neurosis obsesiva de la colectividad humana. La entiende también como ilusión. En consecuencia, no puede exigirse al ser humano fe en - o adhesión a -, ella. El origen de la religión se encuentra en la necesidad de protección del niño inerme y débil y de la nostalgia por el padre (Freud, 1973).

Uno de los intentos recientes más logrados de diálogo entre psicología y teología es el llevado a cabo por el teólogo y psicoterapeuta alemán Drewermann, cuyo principal propósito es vencer la desconfianza de la Iglesia y de la teología católicas hacia el psicoanálisis. "El psicoanálisis, la terapia anímica, la pastoral y la misma teología - asevera - hunden sus raíces en la común herencia cultural" (Drewermann, 1996, p. 84). Drewermann recurre a la psicología profunda para llegar al fondo de la experiencia religiosa. Gracias a ella se llega a entender el sentido antropológico escondido en el rico mundo de las leyendas y fábulas, de los sueños y mitos, de las historias y utopías de la Biblia. La psicología profunda permite incorporar el mundo de los sentimientos en la reflexión teológica.

Como en el caso de la filosofía de la religión, la realidad y la experiencia de Dios son el objeto central de estudio de la teoría psicoanalítica, a partir de la concepción freudiana del Dios personal como un padre amplificado o transfigurado (Tornos, 1979) ${ }^{12}$.

El psicoanálisis presta especial atención a la experiencia mística desde dos enfoques bien diferentes. Uno de ellos se centra en el estudio de la génesis y evolución de dicha experiencia: motivaciones, vicisitudes, movimientos madurativos o regresivos. El otro hace una consideración estructural y parte de la experiencia mística como de un texto escrito (Morano, 1991, 1999).

\section{(d) Sociología de Ia religión}

La sociología de la religión juega un papel importante en la reflexión teológica en cuanto ayuda a descubrir la radicación y función sociales de las religiones ${ }^{13}$. Éstas no son aerolitos intemporales caídos del

\footnotetext{
11 En este caso, se pueden consultar: Freud (1973); Fromm (1967); James (1986); Jung (1962; 1967); Morano (1991, 1992, 1999); Plé (1969); Pohier (1969, 1976); Ricoeur (1987) y Vergote (1969).

12 He dedicado un amplio estudio al problema de Dios en Freud en Tamayo (2000a).

13 También indicamos estas publicaciones: Baum (1980); Berger (1971, 1975); Berger, Berger y Kellner (1979); Durkheim (1982); Fierro (1979); Hill (1976); Instituto Fe y Secularidad (1975); Luckmann (1973); Mardones (1991, 1993, 1995, 1998); Matthes (1971); Milanesi (1974) y Weber (1964, 1984, 1987, 1988).
} 
cielo, sino que surgen en unos contextos determinados y están motivadas por unos condicionamientos sociales, culturales, económicos, políticos. Desde esa óptica pueden considerarse productos socio-culturales que se mueven en el horizonte de la búsqueda del sentido de la existencia humana y de la cohesión socio-comunitaria. Influyen, a su vez, significativamente - y a veces, de forma decisiva -, en el contexto en que surgen, ejerciendo una funcionalidad social no unívoca o lineal, sino ambigua: de liberación o alienación, de pacificación o conflictividad, de humanización o deshumanización, de integración o desintegración en la sociedad, de legitimación o deslegitimación del sistema.

La sociología de la religión libera a la teología cristiana de su tendencia a huir de las mediaciones y a situarse por encima del bien y del mal, y proporciona el marco adecuado para descubrir el carácter histórico del cristianismo.

\section{(e) Historiade Ias religiones}

La historia de las religiones es un largo viaje por la geografía y el tiempo en busca de las huellas religiosas dejadas por el ser humano en las diferentes culturas. Constituye una notable ampliación del estrecho horizonte religioso en que se mueve cada pueblo. Muestra la gran creatividad mítica y simbólica de la humanidad. Revela su capacidad humana ininterrumpida de plantear preguntas sobre el origen, el destino y sentido del mundo, de la vida y de la existencia humana. Pone de manifiesto, asimismo, la desbordante imaginación de la humanidad en la búsqueda de caminos de salvación, tanto histórica como metahistórica ${ }^{14}$

Esta disciplina muestra que no existe un solo universo religioso, sino múltiples y muy variados, no siempre coincidentes, y cada uno con su especificidad. No establece una jerarquía entre las religiones que lleve a privilegiar a unas sobre otras, ni pretende dilucidar de qué parte está la verdad. Lo que sí hace es ponerlas en comunicación y diálogo para su mutuo conocimiento y enriquecimiento.

La historia de las religiones aporta a la teología cristiana una amplia y rigurosa información sobre los múltiples universos simbólicos creados por la humanidad, las plurales representaciones y manifestaciones de la divinidad y su dimensión alienante o emancipadora. La ayuda a superar la concepción religiosa cristianocéntrica, a trascender la tradición cultural occidental y a abrirse a los horizontes y valores de otras tradiciones religiosas. Permite, asimismo, la incorporación de nuevos símbolos a la celebración de la fe.

La historia de las religiones facilita el diálogo entre las religiones y sus correspondientes teologías, ayuda a reducir las distancias que las han separado y a descubrir los elementos comunes. La verdad no es algo dado a priori ni la posee una sola religión. Es, más bien, el resultado de un rico entramado de experiencias vivas formuladas de manera plural.

La historia de las religiones - como el resto de las disciplinas que se ocupan del fenómeno religioso -, necesita guiarse por una hermenéutica. Gracias a ella, "[...] deja de ser un museo de fósiles, ruinas y mirabilia obsoletas, y se convierte en lo que debería haber sido desde el principio para cualquier investigador: una serie de 'mensajes' que esperan ser descifrados y entendidos" (Eliade, 1998, p. 9, cursiva del autor). La hermenéutica descubre en estos mensajes situaciones existenciales fundamentales que poseen relevancia y significación para nosotros hoy.

Tres son las grandes líneas por donde discurren los estudios de la historia de las religiones hoy: consideración de éstas como productos culturales determinados históricamente; reconocimiento de la

\footnotetext{
14 Para más información, consultar estos autores: Bleeker y Widengren (1973); Delimeau (1995); Eliade (1974, 1978, 1998); James (1973); Puech
} (1977) y Wach (1967) 
dignidad cultural de los diferentes sistemas religiosos; necesidad de compaginar el planteamiento histórico-filológico con el análisis comparativo de los fenómenos religiosos (Filoramo et al., 2000).

\section{(f) Antropología de Ia religión}

La antropología de la religión ${ }^{15}$ se pregunta si existe un a priori religioso en el ser humano e intenta buscar las raíces últimas de la fe del individuo o de las comunidades humanas. Estudia, de manera comparada y empírica, la religión como sistema cultural, sistema de símbolos y sistema de fe y de acción. Su centro de atención son los comportamientos religiosos, ritos, mitos, valores y creencias, así como la organización religiosa. Y lo hace no aislando la religión del entorno sociocultural en que se desenvuelve, sino estudiando su interacción con el ordenamiento social y jurídico, con instituciones como la familia y con otros ámbitos de la vida como la política y la economía.

La religión se diferencia de otros sistemas culturales y sociales por su referencia a - su creencia en -, seres que trascienden el horizonte humano y están fuera de los procesos regulares de la naturaleza. Establece una clasificación de los objetos, espacios tiempos y personas en dos órdenes o categorías: lo sagrado y lo profano. La antropología religiosa se ocupa del estudio de las experiencias de lo sagrado en la historia de la humanidad. La experiencia de lo sagrado permite a la mente humana captar la diferencia existente entre lo que se revela a sí mismo como real y significativo y lo que no es, es decir, el flujo caótico de las cosas. Ha de tenerse en cuenta, a este respecto, que, según la certera aseveración Eliade (1998, p. 8 , cursiva del autor), "[...] lo sagrado es un elemento de la estructura de la conciencia, y no una etapa de su historia".

Por eso, ni siquiera en tiempos de secularización como los actuales, sobre todo en las sociedades occidentales, puede hablarse del ser humano completamente desacralizado. La pérdida de sentido de los antiguos dogmas, creencias, rituales e instituciones religiosas, no ha conseguido eliminar el horizonte de lo sagrado de nuestra cosmovisión secularizada. Una buena prueba de ello es la recuperación de la religión cósmica, es decir, el redescubrimiento del carácter sagrado de la vida y de la naturaleza, que no implica necesariamente la vuelta al paganismo o a la idolatría.

Las religiones son fenómenos culturales relevantes de la humanidad que han intervenido de manera decisiva en la formación de las sociedades, como ha demostrado Roy A. Rappaport. Nacimiento y evolución de la religión, por una parte, y origen y desarrollo de la humanidad, por otra, son dos fenómenos interconectados. Lo sagrado y lo numinoso han jugado un papel fundamental en los procesos de adaptación de las distintas unidades sociales en que la especie humana se ha organizado. En ausencia de la religión, cree Rappaport, la humanidad quizá no hubiera sido capaz de salir de su estado prehumano o protohumano. A su vez, le parece que una respuesta adecuada a la actual crisis mundial podría ser una religión que tuviera su base en una ciencia postmoderna fundada en la ecología más que en la astronomía. Se trata de una opinión sólidamente fundada, que puede dar lugar a una amplia discusión intelectual en el campo de la antropología de la religión (Rappaport, 2002) ${ }^{\mathbf{1 6}}$.

\footnotetext{
15 Sobre la antropología de la religión, consulte: Duch (1982, 1997, 2001); Evans-Pritchard (1973); Geertz (1987); Malinowski (1974); Ries (1995a, 1995b); Schwimmer (1982); Waal (1975) y Cobb et al. (1980).

${ }^{16}$ La obra Ritual y religión en la formación de la humanidad expone los resultados de más de tres décadas de investigación en torno a la relación entre religión, sociedad y ecología, y es considerado uno de los grandes hitos de la antropología de la religión que algunos especialistas comparan en alcance y perspectivas de futuro con Las formas elementales de la vida religiosa, de E. Durkheim, publicada en 1912.
} 


\section{Referencias}

Bataille, G. Teoría de la religión. Madrid: Taurus, 1975.

Baum, G. Religión y alienación: lectura teológica de la sociología. Madrid: Cristiandad, 1980.

Bazán, F. G. Aspectos inusuales de lo sagrado. Madrid: Trotta, 2000.

Berger, P. Para una teoría sociológica de la religión. Barcelona: Kairós, 1971.

Berger, P. Rumor de ángeles: la sociedad moderna y el descubrimiento de lo sobrenatural. Barcelona: Herder, 1975.

Berger, P.; Berger B.; Kellner, H. Un mundo sin hogar: modernidad y conciencia. Santander: Sal Terrae, 1979.

Bleeker, C. J.; Widengren, G. (ed.). Historia religionum: manual de historia de las religiones. Madrid: Cristiandad, 1973.

Boff, C. Teología de lo político: sus mediaciones. Salamanca: Sígueme, 1980.

Caffarena, J. G. El teísmo moral de Kant. Madrid: Cristiandad, 1983.

Caffarena, J. G.; Mardones, J.-M. Cuestiones epistemológicas: materiales para una filosofía de la religión I. Barcelona: Anthropos, 1992.

Caffarena, J. G.; Velasco, J. M. Filosofía de la religión. Madrid: Revista de Occidente, 1973.

Cobb, J. B. et al. "¿Qué es religión?" Concilium, v. 156, n. 6, 1980.

Delimeau, J. (dir.). El hecho religioso: enciclopedia de las grandes religiones. Madrid: Alianza, 1995.

Drewermann, E. La palabra de salvación y sanación: la fuerza liberadora de la fe. Barcelona: Herder, 1996.

Duch, L. Antropología de la religión. Anthropologica, v. 6, p. 11-139, 1982.

Duch, L. Antropología de la religión. Barcelona: Herder, 2001.

Duch, L. Historia y estructuras religiosas: aportación al estudio de la fenomenología de la religión. Madrid: Bruño, 1978.

Duch, L. La religió: universal cultural. Questions de Vida Cristiana, v. 188, p. 21-41, 1997.

Duméry, H. Critique et religión: problèmes de méthode en philosophie de la religion. Paris: Sedes, 1957a.

Duméry, H. Le problème de Dieu en philosophie de la religion. Paris: Desclée de Brouwer, 1957b.

Duméry, H. Phénoménologie et religion. Paris: PUF, 1958.

Dupré, L. Simbolismo religioso. Barcelona: Herder, 1999.

Durkheim, É. Las formas elementales la vida religiosa. Madrid: Akal, 1982.

Eckhart, M. El fruto de la nada. Madrid: Siruela, 1998.

Eliade, M. Historia de las creencias y de las ideas religiosas. Madrid: Cristiandad, 1978. 4 v.

Eliade, M. La búsqueda: historia y sentido de las religiones. Barcelona: Kairós, 1998.

Eliade, M. Lo sagrado y lo profano. Madrid: Guadarrama, 1967.

Eliade, M. Tratado de historia de las religiones. Madrid: Cristiandad, 1974. v. 2.

Estrada, J. A. Dios en las tradiciones filosóficas 1: aporías y problemas de la teología natural. Madrid: Trotta, 1994.

Estrada, J. A. Dios en las tradiciones filosóficas 2: de la muerte de Dios a la crisis del sujeto. Madrid: Trotta, 1996.

Estrada, J. A. La imposible teodicea: la crisis de Dios hoy. Madrid: Trotta, 1997;

Estrada, J. A. Razones y sinrazones de la creencia religiosa. Madrid: Trotta, 2001.

Evans-Pritchard, E. E. Las teorías de la religión antigua. Madrid: Siglo XXI, 1973.

Fierro, A. Sobre la religión: descripción y teoría. Madrid: Taurus, 1979.

Filoramo, G. et al. Historia de las religiones. Barcelona: Crítica, 2000. 
Fraijó Nieto, M. A vueltas con la religión. 2. ed. Estella: Verbo Divino, 2000.

Fraijó Nieto, M. Filosofía de la religión: estudios y textos. Madrid: Trotta, 1994.

Freud, S. Obras completas. 3. ed. Barcelona: Biblioteca Nueva, 1973. v. 3.

Fromm, E. Psicoanálisis y religión. Buenos Aires: Psique, 1967.

Geertz, C. La religión como sistema cultural. In: Geertz, C. La interpretación de las culturas. Barcelona: Gedisa, 1987. p. 87-117.

Gesché, A. Dios para pensar 1: El mal-El hombre. Salamanca: Sígueme, 1995.

Gesché, A. Dios para pensar 2: Dios-El cosmos. Salamanca: Sígueme, 1997.

Gimbernat, J. A. Religión (Crítica). In: Foristán, C.; Tamayo, J. J. (dir.) Conceptos fundamentales del cristianismo. Madrid: Trotta, 1993. p. 1137-1144.

Gutiérrez, G. Teología de la liberación: perspectivas. Lima: CEP, 1971.

Haag, A. M. Visión en azul: estudio de mística europea. Madrid: Siruela, 1998.

Hegel, G. W. F. El concepto de religión: estudio introductorio de A. Ginzo. Madrid: FCE, 1981.

Hegel, G. W. F. Lecciones sobre filosofía de la religión. Madrid: Alianza, 1984. v. 3.

Hill, M. Sociología de la religión. Madrid: Cristiandad, 1976.

Hume, D. Diálogos sobre la religión natural: historia natural de la religión. Salamanca: Sígueme, 1974.

Ibn'Arabi. Las iluminaciones de la Meca Madrid: Siruela, 1994.

Instituto Fe y Secularidad. Convicción de fe y crítica racional. Salamanca: Sígueme, 1973.

Instituto Fe y Secularidad. Sociología de la religión y teología: estudio bibliográfico. Madrid: Cuadernos para el Diálogo, 1975.

Izutsu, T. Sufismo y taoísmo: Ibn'Arabi. Madrid: Siruela, 1997a. v. 1.

Izutsu, T. Sufismo y taoísmo: Laozi y Zhuangzi. Madrid: Siruela, 1997b. v. 2.

James, O. Introducción a la historia comparada de las religiones. Madrid: Cristiandad, 1973.

James, W. Las variedades de la experiencia religiosa. Barcelona: Península, 1986.

Jung, C. G. Psicología y religión. 4. ed. Buenos Aires: Paidós, 1967.

Jung, C. G. Simbología del espíritu. México: Fondo de Cultura Económica, 1962.

Kant, I. La contienda de las facultades de filosofía y teología: estudio preliminar de J. Gómez Caffarena. Madrid: Trotta, 1999.

Kant, I. La religión dentro de los límites de la mera razón. Madrid: Akal, 1969.

Luckmann, T. La religión invisible. Salamanca: Sígueme, 1973.

Magdalena, E. M. Occidente mira a Oriente. Barcelona: Plaza y Janés, 1998.

Malinowski, B. Magia, ciencia, religión. Barcelona: Ariel, 1974.

Mardones, J.-M. Análisis de la sociedad y fe cristiana. Madrid: PPC, 1995.

Mardones, J.-M. Capitalismo y religión: Ia religión política neoconservadora. Santander: Sal Terrae, 1991.

Mardones, J.-M. Fe y politica. Santander: Sal Terrae, 1993.

Mardones, J.-M. Neoliberalismo y religión. Navarra: Verbo Divino, 1998.

Mardones, J.-M. La tradición analítica: materiales para una filosofía de la religión II. Barcelona: Anthropos, 1992.

Matthes, J. Introducción a la sociología de la religión - I: Religión y sociedad, II. Iglesia y sociedad. Madrid: Alianza Universidad, 1971.

Miethe, T.; Flew, A. ¿Existe Dios? El debate entre un creyente y un ateo. Barcelona: Cátedra, 1994. 
Milanesi, J. Sociología de la religión. Madrid: CCS, 1974.

Morano, C. D. Creer después de Freud. Madrid: Paulinas, 1992.

Morano, C. D. El psicoanálisis freudiano de la religión: análisis textual y comentario crítico. Madrid: San Pablo, 1991.

Morano, C. D. Experiencia mística y psicoanálisis. Madrid: Sal Terrae, 1999. (Cuadernos fe y Secularidad, v. 45).

Otto, R. Lo santo: lo racional y lo irracional en la idea de Dios. Madrid: Alianza, 1980.

Panikkar, R. El silencio de Buddha. Madrid: Siruela, 1996.

Plé, A. Psicología y religión: estudio introductorio de J. Rof Carballo. Madrid: BAC, 1969.

Pohier, J. M. En el nombre del Padre: estudios teológicos y psicoanalíticos. Salamanca: Sígueme, 1976.

Pohier, J. M. Psicología y teología. Barcelona: Herder, 1969.

Pohier, J. M. Teología y psicoanálisis. Concilium, v. 135, p. 221-231, 1978.

Puech, H. C. (dir.). Historia de las religiones. Madrid: Siglo XXI, 1977. v. 12.

Queiruga, A. T. El problema de Dios en la modernidad. Estella: Verbo Divino, 1997.

Rappaport, R. A. Ritual y religión en la formación de la humanidad. Madrid: Akal, 2002.

Ricoeur, P. Freud: una interpretación de la cultura. 7. ed. México: Siglo XXI, 1987.

Ries, J. (coord.). Tratado de antropología de lo sagrado - l: los orígenes del homo religiosus. Madrid: Trotta, 1995a.

Ries, J. (coord.). Tratado de antropología de lo sagrado - Il: el hombre indoeuropeo y lo sagrado. Madrid: Trotta, 1995b.

Sádaba, J. Lecciones de filosofía de la religión. Madrid: Mondadori, 1989.

Sádaba, J. ¿Qué es un sistema de creencias? Madrid: Mañana Editorial, 1978.

Schäffler, R. Religions-philosophie. Freiburg und München: Karl Alber, 1983.

Schlütter, A. M.; Faus, J. I. G. Mistica oriental y mistica cristiana: XXII Foro del Hecho religioso. Madrid: Sal Terrae, 1998.

Scholem, G. Las grandes tendencias de la mística judía. Madrid: Siruela, 1996.

Schwimmer, E. Religión y cultura. Barcelona: Anagrama, 1982.

Tamayo, J. J. Ernst Bloch: filosofía de la religión en clave de utopía. Biblia y Fe, v. 59, p. 11-45, 1994.

Tamayo, J. J. Para comprender la crisis de Dios hoy. 2. ed. Estella: Verbo Divino, 2000a.

Tamayo, J. J. Para comprender la teología de la liberación. 5. ed. Estella: Verbo Divino, 2000b.

Tamayo, J. J. Ronda la muerte, Ronda. El Nuevo Diario, 2004. Disponible en: http://archivo.elnuevodiario.com.ni/ cultural/157814-ronda-muerte-ronda/. Acceso en: 29 oct. 2021.

Tamayo, J. J. Fundamentalismos y diálogo entre religiones. 2. ed. Madrid: Trotta, 2009a.

Tamayo, J. J. Nuevo paradigma teológico. 2. ed. Madrid: Trotta, 2009b.

Tornos, A. Psicoanálisis y Dios. Bilbao: Mensajero, 1979.

van der Leew, G. Fenomenología de la religión. México: FCE, 1964.

Velasco, J. M. El fenómeno místico: estudio comparado. Madrid: Trotta, 1999.

Velasco, J. M. El malestar religioso en nuestra cultura. 3. ed. Madrid: San Pablo, 1998.

Velasco, J. M. Introducción a la fenomenología de la religión. 4. ed. Madrid: Cristiandad, 1984.

Velasco, J. M. La fenomenología de la religión en el campo de los saberes sobre el hecho religioso. In: Caffarena, J. G.; Mardones, J. M. (coord.). I Cuestiones epistemológicas: materiales para una filosofía de la religión. Barcelona: Anthropos, 1992. p. 13-58.

Velasco, J. M. Religión (Fenomenología). In: Floristán, C.; Tamayo, J. J. (dir.). Conceptos fundamentales del cristianismo. Madrid: Trotta, 1993. p. 1155-1172. 
Vergote, A. Psicología religiosa. Madrid: Taurus, 1969.

Waal, A. Introducción a la antropología religiosa. Estella: Verbo Divino, 1975.

Wach, J. El estudio comparado de las religiones. Barcelona: Paidós, 1967.

Weber, M. Economía y sociedad: esbozo de sociología comprensiva. 2. ed. México: Fondo de Cultura Económica, 1964. v. 2.

Weber, M. Ensayos de sociología de la religión. Tomo I. Madrid: Taurus, 1984.

Weber, M. Ensayos de sociología de la religión. Tomo II. Madrid: Taurus, 1987.

Weber, M. Ensayos de sociología de la religión. Tomo III. Madrid: Taurus, 1988.

Weger, H.-K. La crítica de la religión en los tres últimos siglos: diccionario de autores y escuelas. Barcelona: Herder, 1985.

Widengren, G. Fenomenología de la religión. Madrid: Cristiandad, 1976.

Zirker, H. Crítica de la religión. Barcelona: Herder, 1985.

Zubiri, X. El problema filosófico de la historia de las religiones. Madrid: Alianza-Fundación Xavier Zubiri, 1993.

Como citar este artículo/How to cite this article

Tamayo, J. J. Ciencias de las Religiones y teología: un diálogo necesario. Reflexão, v. 46, e215535, 2021. https://doi. org/10.24220/2447-6803v46e2021a5535 